\title{
Low-Dose IL-2 Therapy Limits the Reduction in Absolute Numbers of Circulating Regulatory T Cells in Rheumatoid Arthritis
}

\section{Sheng-Xiao Zhang}

the Second Hospital of Shanxi Medical University

Jia Wang

The Second Hospital of Shanxi Medical University

Cai-Hong Wang

Second Hospital of Shanxi Medical University

Rui-Huan Jia

the Second Hospital of Shanxi Medical University

Ming Yan

The Second Hospital of Shanxi Medical University

\section{Fang-Yuan $\mathrm{Hu}$}

the Shanxi Medical University Second Affiliated Hospital: Second Hospital of Shanxi Medical University

Guang-Ying Liu

the Second Hospital of Shanxi Medical University

Xue-Yu Liu

Taiyuan University of Technology

Jing Luo

the Second Hospital of Shanxi Medical University

\section{Chong Gao}

Brigham and Women's Hospital,Harvard Medical School

Xiao-Feng Li ( $\nabla$ lxf_9859@sxmu.edu.cn )

The Second Hospital of Shanxi Medical University

\section{Research article}

Keywords: rheumatoid arthritis, regulatory T cells, low-dose IL-2, immunoregulation.

Posted Date: October 26th, 2020

DOI: https://doi.org/10.21203/rs.3.rs-93717/v1 
License: (c) (i) This work is licensed under a Creative Commons Attribution 4.0 International License. Read Full License 


\section{Abstract}

Background Circulating regulatory $T$ cells (Tregs) are responsible for mediating immune tolerance and maintaining immunological homeostasis. Decreases in Tregs may be involved in the onset of rheumatoid arthritis (RA). Low-dose interleukin-2 (IL-2) has been considered for the treatment of inflammatory diseases mediated by $T$ cells. This study focused on the status of circulating $C D 4^{+} T$ subsets and the clinical feasibility of IL-2 therapies in patients with RA.

Methods The subjects included 888 patients with RA and 100 healthy controls (HCs); 233 RA patients received IL-2 treatment of at 0.5 million international units (MIU)/day from days 1 through 5 . The demographic features, disease activity, and levels of $\mathrm{CD} 4+\mathrm{T}$ cells measured by modified flow cytometry were collected in all RA patients before and after treatment.

Results RA patients had lower absolute Treg counts (but not Th17) compared with HCs, which was associated with disease activity; previously treated RA patients had the fewest circulating Tregs $(P<$ 0.05). Patients treated with low-dose IL-2 had a three-fold increase in absolute anti-inflammatory Treg counts, as well as a two-fold increase in the other $C D 4^{+} T$ subsets. Moreover, post-treatment levels of markers of disease activity in RA patients treated with IL-2 were significantly lower than the baseline values $(P<0.001)$, with no apparent side effects.

Conclusions Decreased absolute counts of circulating $C D 4^{+} T$ lymphocyte subsets were observed in patients with RA. Circulating Tregs, which mediate immune tolerance, may be involved in the pathogenesis and progression of RA; however, this was ameliorated by low-dose IL-2, without obvious side effects.

\section{Key Messages}

1. Circulating Tregs may be involved in the pathogenesis and progression of RA.

2. The absolute count of Tregs was significantly correlated with disease activity mesures.

3. Low-dose IL-2 was able to effectively expade Tregs and help for RA patients' symptoms remission without evaluated side effects.

\section{Introduction}

Rheumatoid arthritis (RA) is a common chronic and progressive autoimmune inflammatory rheumatic disease of multiple synovial joints, ultimately driven by aberrant immune responses ${ }^{1}$. Chronic inflammation can lead to joint damage, severe disability and even a higher risk of mortality without adequate treatment ${ }^{2}$. Disease-modifying antirheumatic drugs (DMARDs), including conventional synthetic DMARDs such as methotrexate, biologic DMARDs such as IL-6R antibodies and JAK inhibitors, and targeted synthetic DMARDs, may improve physical function and inhibit the progression of joint damage by blocking the overwhelming production of pro-inflammatory cytokines that hinder the return to 
immunological homeostasis ${ }^{34}$. Changes in immune-cell function and/or number are mainly responsible for the progressive destruction caused by RA, a T cell-dependent disease, and promotion of synovial joint articular cartilage degradation and subchondral bone erosion ${ }^{5}$. However, there is no consensus on the levels and function of T cell populations in peripheral blood (PB). Therefore, this should be the priority of research efforts to elucidate the pathogenesis of RA and assess the efficacy of novel therapies.

Several recent studies have focused on the role of impaired immune regulation, resulting mainly from $T$ cells with a regulatory phenotype, in the pathophysiology of RA ${ }^{3}$. Immunoregulation mediated by regulatory $T$ cells (Tregs) derived from $C D 4+C D 25+T$ cells, with high expression of fork head box protein 3 (FoxP3), is one of the most crucial mechanisms to maintain self-tolerance and immune system homeostasis, and may prevent the production of autoantibodies such as anti-cyclic citrullinated peptide antibodies (anti-CCPs) ${ }^{67}$. Autoimmune responses can be adjusted by re-establishing the $T$ cell balance in favor of Tregs, as shown in animal models of rheumatic disease ${ }^{8}$. Impaired self-tolerance caused by deficiencies in the function and/or number of Tregs may be an important therapeutic target for RA, and is being extensively investigated in several autoimmune/inflammatory disorders, such as systemic lupus erythematosus, psoriasis, ankylosing spondylitis, and Behçet's disease ${ }^{8}{ }^{9}$. However, most previous studies focused on the proportion of Tregs, that can be affected by levels of CD4 + T cells and their subsets (such as Th1, Th2, and Th17 cells), rather than the absolute counts, and did not include large amounts of clinical data ${ }^{10}$.

Interleukin-2 (IL-2), a soluble T-cell growth factor produced mainly by antigen-activated T cells, has a unique ability to control the proliferation and differentiation of $\mathrm{T}$ cells by binding to three different highaffinity receptor subunits, including an IL-2 receptor a chain (CD25 or IL-2Ra), an IL-2 receptor $\beta$ chain (CD122 or IL-2Rß), and a y subunit (CD132 or Yc), on target cell membranes in vitro ${ }^{11}{ }^{12}$. Systemic fatal autoimmune diseases can develop when T cell regulation by IL-2 is deficient ${ }^{13}$. Indeed, the role of IL-2 (as an immunomodulatory cytokine) in the function and differentiation of CD4 + T lymphocyte subsets, especially Tregs with high expression of IL-2Ra, has been the focus of extensive studies on immunemediated diseases in vitro or in vivo ${ }^{914}$. Our previous studies found the efficacy and safety of low-dose IL-2 targeted regulation of Tregs levels in patients with psoriatic arthritis (PsA ${ }^{15}$, dermatomyositis/polymyositis (DM/PM) ${ }^{16}$, primary Sjögren's syndrome $(\mathrm{pSS})^{17}$. However, evidence of the clinical efficacy and safety of IL-2 combined treatment in patients with RA is still lacking.

In this retrospective study, we measured the absolute counts of CD $4+T$ subsets using modified flow cytometry in patients with RA and healthy controls (HCs), to elucidate the immune mechanism of RA. All RA patients received DMARDs with or without low-dose IL-2 treatment, to further clarify the clinical feasibility of IL-2 treatment for RA.

\section{Methods}

\section{Participants}


The participants included 888 patients with RA, seen at the Second Hospital of Shanxi Medical University between January 2016 and September 2018 and who met the 1987 and 2010 RA classification criteria ${ }^{18}$ 19 , and $100 \mathrm{HCs}$. The study was approved by the hospital's Ethics Committee (ethics number: 2016-KY007). Exclusion criteria included the presence of other autoimmune diseases such as SLE; history of chronic infection and malignancy; severe active infection (such as tuberculosis, hepatitis viruses, HIV or Epstein-Barr virus); severe hepatic and renal dysfunction; pregnant or lactating females.

\section{Treatment}

In total, 233 RA inpatients with informed consent were received additional IL-2 treatment at 0.5 million international units (MIU)/day from days 1 to 5 , combined with conventional immunosuppressants treatments (Supplementary table 1 ).

\section{Data collection}

The demographic and clinical data of the RA patients were recorded before and after treatment, including disease activity, such as the tender joint count (TJC), swollen joint count (SJC), and Disease Activity Score-28 (DAS28); and general laboratory indicators, such as the erythrocyte sedimentation rate (ESR), complete blood count, and liver and kidney function tests.

The absolute counts and proportions of $\mathrm{CD} 4^{+} \mathrm{T}$ subsets, including helper $\mathrm{T}(\mathrm{Th}) 1\left(\mathrm{CD}^{+}{ }^{+} \mathrm{Y}^{-} \mathrm{IFN}{ }^{+}\right), \mathrm{Th} 2$ $\left(\mathrm{CD} 4^{+} \mathrm{IL}-4^{+}\right)$, Th17 $\left(\mathrm{CD} 4^{+} \mathrm{IL}-17^{+}\right)$, and Tregs $\left(\mathrm{CD} 4^{+} \mathrm{CD} 25^{+} \mathrm{FOXP}^{+}\right)$(Supplementary Figure 1$)$, were measured by modified flow cytometry ${ }^{15} 17$ in HCs and all RA patients before treatment, and only those patients receiving low-dose IL-2 underwent re-evaluation of $C D 4^{+} \mathrm{T}$ cell subsets levels within 2 days of treatment completion.

\section{Statistical analysis}

Categorical data are expressed as frequencies and were analyzed using the chi-squared test. Nonnormally distributed data are expressed as the median (range) and were analyzed using the MannWhitney $\mathrm{U}$ test or Kruskal-Wallis $\mathrm{H}$ test. Normally or near-normally distributed data are described as mean $\pm S D$ and were analyzed using the independent samples t-test or ANOVA test. The paired samples ttest was used to analyze changes in disease activity and laboratory indices after IL-2 treatment in RA patients. The correlations between the absolute counts of Tregs and disease activity parameters were analyzed using Pearson's correlation. The correlations of autoantibodies with markers of disease activity and Tregs were analyzed using Spearman's correlation. SPSS 22.0 software (IBM Corp., Armonk, NY, USA) was used for the statistical analyses. A 2-tailed $P$-value $<0.05$ was considered statistically significant.

\section{Results}

\section{Baseline characteristics of all subjects}


A total of 888 RA patients ( 618 females and 270 males) with a mean age of $55.8 \pm 13.0$ years, and 100 HCs (65 females and 35 males) with a mean age of $54.4 \pm 8.0$ years were enrolled. The RA patients included 188 new patients (129 females and 59 males, without any immunosuppressants or steroids) with a mean age of $54.4 \pm 14.0$ years, and 700 patients already treated with immunosuppressants or corticosteroid (489 females and 211 males) with a mean age of $56.2 \pm 12.7$ years. There was no statistically significant difference in gender or age among the groups $(P>0.05)$ (Table 1). In total, 233 patients with RA received the IL-2 treatment ( $0.5 \mathrm{MIU} /$ day for 5 days) and their absolute counts and proportions of peripheral CD $4+T$ subgroups were measured.

Table 1

Baseline characteristics of all subjects (mean $\pm \mathrm{SD}$ )

\begin{tabular}{|lllll|}
\hline & Healthy controls & RA & t & P \\
\hline $\mathrm{n}$ & 100 & 888 & & \\
\hline Age (years) & $54.4 \pm 8.0$ & $55.8 \pm 13.0$ & 1.60 & 0.112 \\
\hline Gender (female/male) & $65 / 35$ & $618 / 270$ & 0.89 & 0.346 \\
\hline Th1 (cells/ $\mu \mathrm{L})$ & $124.7 \pm 80.77$ & $88.68 \pm 77.23$ & 4.40 & $<0.001$ \\
\hline Th2 $($ cells $/ \mu \mathrm{L})$ & $8.89 \pm 5.45$ & $9.58 \pm 6.52$ & 1.01 & 0.312 \\
\hline Th17 $($ cells/ $\mu \mathrm{L})$ & $7.22 \pm 4.04$ & $7.17 \pm 6.01$ & 0.10 & 0.918 \\
\hline Treg $($ cells/ $\mu \mathrm{L})$ & $35.2 \pm 12.98$ & $27.98 \pm 16.71$ & 4.18 & $<0.001$ \\
\hline Th1\% & $17.96 \pm 9.97$ & $13.65 \pm 10.02$ & 4.08 & $<0.001$ \\
\hline Th2\% & $1.32 \pm 0.79$ & $1.56 \pm 1.06$ & 2.21 & 0.027 \\
\hline Th17\% & $1.06 \pm 0.57$ & $1.18 \pm 1.07$ & 1.76 & 0.080 \\
\hline Treg\% & $5.12 \pm 1.46$ & $4.38 \pm 2.01$ & 4.58 & $<0.001$ \\
\hline Th1/Th2 & $19.97 \pm 25.1$ & $11.34 \pm 10.31$ & 3.41 & 0.001 \\
\hline Th17/Treg & $0.23 \pm 0.15$ & $0.35 \pm 0.47$ & 5.49 & $<0.001$ \\
\hline RA: rheumatoid arthritis; Th: helper T cells; Treg: regulatory T cells. & \\
\hline
\end{tabular}

\section{Differences in CD4 + T subset levels between RA patients and healthy controls}

Both new and previously treated RA patients had decreased absolute counts of Tregs, but not Th17 or Th2 cells, compared with HCs $(27.98 \pm 16.71$ vs. $35.2 \pm 12.98, P<0.001)$; the fewest Tregs were in PB from patients already treated with immunosuppressive therapies $(P<0.05)$. The counts of circulating Th1 cells were also lower in RA patients overall, and in the previously treated RA patients, compared with the $\mathrm{HCs}$, but there was no significant difference between the new RA patients and HCs. Compared with HCs, RA patients (both new and previously treated) had a lower proportion of Tregs but no difference in that of 
Th17; thus, the Th17/Treg ratio was significantly higher in RA patients $(P<0.05)($ Table 1, Fig. 1$)$. The proportions of Th1 and Th2 decreased and increased, respectively, and as a result the ratio of Th1/Th2 increased, in both RA patients overall and previously treated RA patients $(P<0.05)$, but not in new RA patients $(P>0.05)$ (Supplementary Fig. 2). Peripheral Tregs were the only CD $4^{+} T$ subset that showed a significant decrease in absolute counts in both previously treated and new RA patients compared with HCs, which suggested that Tregs may be the crucial lymphocyte subset involved in the onset of RA (Fig. 1).

\section{Changes in CD4 + T subset levels in RA patients varying in disease activity level}

Based on DAS28-ESR, all patients with RA were divided into remission (DAS28 $\leq 2.6, n=47$ ), low activity $(2.6<$ DAS28 $\leq 3.2, n=56)$, moderate activity $(3.2<$ DAS28 $\leq 5.1, n=361)$, and high activity groups $(5.1<$ DAS28, $n=424$ ) (Table 2). The clinical remission rate of RA was only $5 \%$, whereas nearly half of all RA patients had high disease activity. As the condition of the RA patients deteriorated, a gradual decline in the absolute counts of CD4 + T subsets, especially Tregs, was observed, although the proportions of those subsets and the Th17/Treg and Th1/Th2 ratios did not change significantly (Table 2, Supplementary Fig. 3). The fewest Tregs, Th17, Th1, and Th2 cells were seen in the PB of patients with high disease activity $(P<0.05)$ (Table 2$)$. The absolute count of Tregs was significantly correlated with the disease duration $(P<0.05)$ and markers of disease activity $(P<0.001)$, including ESR, C-reactive protein (CRP), TJC, SJC, and DAS28 (Fig. 2). 
Table 2

Differences in absolute counts of CD4 + T subgroups among patients with different disease activity levels $($ mean $\pm S D)$

\begin{tabular}{|c|c|c|c|c|c|}
\hline & $\begin{array}{l}\text { Healthy } \\
\text { controls }\end{array}$ & $\begin{array}{l}\text { RA- } \\
\text { remission }\end{array}$ & RA - Iow & RA - moderate & RA-high \\
\hline & & DAS $28<2.6$ & $\begin{array}{l}2.6 \leq \mathrm{DAS} 28 \\
<3.2\end{array}$ & $\begin{array}{l}3.2 \leq \text { DAS } 28 \\
<5.1\end{array}$ & DAS28 $\geq 5.1$ \\
\hline $\mathrm{n}$ & 100.00 & 47 & 56 & 361 & 424 \\
\hline $\begin{array}{l}\text { Gender } \\
\text { (female/male) }\end{array}$ & $65 / 35$ & $30 / 17$ & $34 / 22$ & $245 / 116$ & $309 / 115$ \\
\hline Age (years) & $54.4 \pm 8.0$ & $\begin{array}{l}51.64 \pm \\
12.62\end{array}$ & $52.86 \pm 13.26$ & $54.94 \pm 13.54$ & $\begin{array}{l}57.48 \pm \\
12.38^{\mathrm{abcd}}\end{array}$ \\
\hline Th1 (cells/ $\mu \mathrm{L}$ ) & $\begin{array}{l}124.7 \pm \\
80.77\end{array}$ & $\begin{array}{l}111.64 \pm \\
100.63\end{array}$ & $\begin{array}{l}100.07 \pm \\
99.01\end{array}$ & $\begin{array}{l}99.28 \pm \\
81.15^{\mathrm{a}}\end{array}$ & $\begin{array}{l}75.61 \pm \\
64.69^{\mathrm{abd}}\end{array}$ \\
\hline Th2 (cells/ $\mu \mathrm{L}$ ) & $8.89 \pm 5.45$ & $\begin{array}{l}12.35 \pm \\
7.62^{\mathrm{a}}\end{array}$ & $10.9 \pm 6.87$ & $9.91 \pm 6.33^{b}$ & $8.82 \pm 6.39^{b c c}$ \\
\hline Th17 (cells/ $\mu \mathrm{L}$ ) & $7.22 \pm 4.04$ & $9.03 \pm 7.01$ & $7.63 \pm 5.92$ & $7.68 \pm 6.3$ & $6.47 \pm 5.56^{b d}$ \\
\hline Treg (cells/ $\mu \mathrm{L}$ ) & $35.2 \pm 12.98$ & $\begin{array}{l}31.03 \pm \\
15.22\end{array}$ & $30.86 \pm 19.55$ & $\begin{array}{l}29.57 \pm \\
16.59^{a}\end{array}$ & $\begin{array}{l}25.91 \pm \\
16.36^{\mathrm{abd}}\end{array}$ \\
\hline Th1\% & $17.96 \pm 9.97$ & $\begin{array}{l}13.85 \pm \\
9.95^{\mathrm{a}}\end{array}$ & $14 \pm 11.16^{a}$ & $\begin{array}{l}14.22 \pm \\
10.02^{\mathrm{a}}\end{array}$ & $13.1 \pm 9.87^{a}$ \\
\hline Th2\% & $1.32 \pm 0.79$ & $1.74 \pm 1.24^{\mathrm{a}}$ & $1.66 \pm 1.45$ & $1.5 \pm 0.9$ & $1.57 \pm 1.11^{\mathrm{a}}$ \\
\hline Th17\% & $1.06 \pm 0.57$ & $1.47 \pm 2.05$ & $1.16 \pm 0.93$ & $1.17 \pm 0.97$ & $1.16 \pm 1$ \\
\hline Treg\% & $5.12 \pm 1.46$ & $4.16 \pm 1.9^{a}$ & $4.22 \pm 1.86^{a}$ & $4.41 \pm 1.95^{\mathrm{a}}$ & $4.41 \pm 2.1^{a}$ \\
\hline Th1/Th2 & $19.97 \pm 25.1$ & $\begin{array}{l}12.71 \pm \\
14.01\end{array}$ & $\begin{array}{l}11.43 \pm \\
11.14^{\mathrm{a}}\end{array}$ & $11.9 \pm 10.73^{a}$ & $10.69 \pm 9.3^{a}$ \\
\hline Th17/Treg & $0.23 \pm 0.15$ & $0.46 \pm 0.76^{a}$ & $0.33 \pm 0.32^{\mathrm{a}}$ & $0.33 \pm 0.42^{\mathrm{a}}$ & $0.35 \pm 0.48^{a}$ \\
\hline
\end{tabular}

Changes in antibody levels in RA patients varying in disease activity levels

Levels of autoantibodies, such as rheumatoid factor (RF), anti-CCP, and anti-mutated citrullinated vimentin antibody (anti-MCV), were recorded in 774 patients with RA. The levels of RF and anti-MCV were lower in RA patients in remission than in patients with active RA, whereas the anti-CCP level was not significantly different among RA patients with different disease activity levels (Supplementary Fig. 4). 
The level of RF was significantly correlated with indicators of disease activity, such as DAS28, ESR, and CRP, while anti-MCV was significantly correlated only with DAS28 and ESR. In addition, only RF was significantly correlated with the absolute count of peripheral Tregs (Supplementary Fig. 5).

Changes in disease activity parameters and general biochemical indicators in RA patients with low-dose IL-2 treatment

After low-dose IL-2 treatment, indicators of disease activity, including ESR, CRP, TJC, SJC, and DAS28, decreased significantly compared with baseline values $(P<0.001)$ (Table 3$)$. Compared with baseline values, white blood cell (WBC), neutrophilic granulocyte, and lymphocyte counts increased significantly $(P<0.001)$, platelet (PLT) counts decreased $(P<0.001)$, and red blood cell (RBC) counts did not change $(P>0.05)$ in the PB of RA patients with IL-2 treatment; however, the levels of these indicators fell within the normal range. Liver function, assessed by aspartate aminotransferase (AST), alanine aminotransferase (ALT), and y-glutamine transferase (GGT) concentrations, was not affected; AST was lower than baseline $(P<0.05)$ but still within the normal range. Blood urea nitrogen $(B U N)$ and serum creatinine (CREA), which indicate renal function, significantly increased and decreased, respectively, relative to baseline $(P<0.05)$ but were within the normal range (Table 3$)$. 
Table 3

Indicators of the efficacy and safety of IL-2 treatment (mean \pm SD)

\begin{tabular}{|c|c|c|c|c|}
\hline & Before IL-2 & After IL-2 & $t$ & $P$ \\
\hline $\operatorname{ESR}(\mathrm{mm} / \mathrm{h})$ & $59.85 \pm 36.62$ & $28.88 \pm 25.4$ & 13.798 & $<0.001$ \\
\hline CRP (mg/L) & $41.98 \pm 47.88$ & $10.26 \pm 21.64$ & 8.078 & $<0.001$ \\
\hline TJC & $10.07 \pm 7.97$ & $3.94 \pm 4.76$ & 14.636 & $<0.001$ \\
\hline SJC & $6.4 \pm 7.63$ & $1.7 \pm 3.32$ & 11.212 & $<0.001$ \\
\hline DAS28 & $5.44 \pm 1.34$ & $3.66 \pm 1.09$ & 22.611 & $<0.001$ \\
\hline WBC $\left(\times 10^{9} / \mathrm{L}\right)$ & $6.87 \pm 2.89$ & $9.62 \pm 4.99$ & 7.995 & $<0.001$ \\
\hline $\mathrm{RBC}\left(\times 10^{12} / \mathrm{L}\right)$ & $4.16 \pm 0.55$ & $4.29 \pm 1.21$ & 1.518 & 0.131 \\
\hline $\operatorname{PLT}\left(\times 10^{9} / \mathrm{L}\right)$ & $299 \pm 101$ & $270 \pm 90$ & 5.586 & $<0.001$ \\
\hline Neutrophilic granulocyte $\left(\times 10^{9} / \mathrm{L}\right)$ & $4.82 \pm 2.53$ & $6.31 \pm 3.07$ & 6.905 & $<0.001$ \\
\hline Lymphocyte $\left(\times 10^{9} / \mathrm{L}\right)$ & $1.57 \pm 0.64$ & $2.41 \pm 1.15$ & 10.959 & $<0.001$ \\
\hline $\operatorname{ALT}(\mathrm{U} / \mathrm{L})$ & $24.71 \pm 17.27$ & $30.49 \pm 34.05$ & 1.457 & 0.15 \\
\hline AST (U/L) & $27.06 \pm 19.66$ & $21.02 \pm 14.91$ & 2.428 & 0.018 \\
\hline GGT (U/L) & $38.72 \pm 39.83$ & $39.73 \pm 36.39$ & 0.218 & 0.828 \\
\hline BUN (mmol/L) & $5.46 \pm 1.95$ & $6.01 \pm 2.21$ & 2.124 & 0.038 \\
\hline CREA (mmol/L) & $57.75 \pm 14.9$ & $55.36 \pm 15.66$ & 2.306 & 0.025 \\
\hline \multicolumn{5}{|c|}{$\begin{array}{l}\text { ESR: erythrocyte sedimentation rate; CRP: C-reactive protein; TJC: tender joint count; SJC: swollen join } \\
\text { count; DAS28: Disease Activity Score-28; WBC: white blood cells; RBC: red blood cells; PLT: platelet; } \\
\text { ALT: alanine aminotransferase; AST: aspartate aminotransferase; GGT: } \text {-glutamine transferase; BUN: } \\
\text { blood urea nitrogen; CREA: serum creatinine. }\end{array}$} \\
\hline
\end{tabular}

\section{Changes in CD4 + T subset levels in RA patients with IL-2 treatment}

Patients treated with low-dose IL-2 showed a three-fold increase in the absolute counts of antiinflammatory Tregs (26.26 \pm 15.51 to $92.8 \pm 64.92)$, and a two-fold increase in other CD $4+T$ subsets, such as Th1, Th2, and Th17 cells $(P<0.001)$ (Fig. 3); however, the proportions of CD $4+$ T subsets did not change significantly $(P>0.05)$ (Supplementary Fig. 6). After IL-2 treatment, the Th17/Treg ratio decreased significantly, down to the level of HCs, whereas the Th1/Th2 ratio did not change significantly (Fig. 3).

\section{Safety}

Low-dose IL-2 was well tolerated in all patients with RA. None of them displayed severe advent effect. Non-severe adverse events were characterized by skin rashes at the injection site that could heal 
spontaneously without special treatment.

\section{Discussion}

$\mathrm{CD} 4^{+} \mathrm{CD} 25^{+} \mathrm{FOXP3}{ }^{+} \mathrm{T}$ cells, also known as Tregs, can modulate the immune system, maintain selftolerance and immunological homeostasis, and suppress the proliferation of effector $T$ cells and the production of pro-inflammatory cytokines and autoantibodies. In human and animal studies, dysfunction or reduction of circulating Tregs has been observed in autoimmune diseases, including systemic lupus erythematosus ${ }^{20}$, dermatomyositis/polymyositis (DM/PM) ${ }^{16}$, primary Sjögren's syndrome (pSS) ${ }^{17}$, and $\mathrm{RA}^{21} 22$. However, results from several studies regarding the levels of peripheral Tregs in RA are controversial ${ }^{23}$. Thus, large amounts of data pertaining to the absolute counts of Tregs in PB have been needed to confirm whether lack or dysfunction of circulating Tregs is crucial to the immune mechanism of RA.

The present study investigated the levels of peripheral Tregs in a large sample of RA patients. Compared with HCs, patients with RA had fewer Tregs and Th1 cells, but not Th17 cells, which are important immune cells previously thought to be involved in the onset of RA. The reduced absolute count of Tregs rather than Th1 cells was the only difference in immune cells between new RA patients (i.e., recent onset or without previous immunosuppressive therapies) and healthy individuals. In addition, the absolute count of Tregs was clearly associated with disease activity and RF, and gradually decreased with disease progression in RA patients. These observations suggested that Tregs play an indispensable role in the pathogenesis and progression of RA. Evidence that Tregs may be involved in the progression of arthritis comes primarily from experimental mouse studies wherein disease was exacerbated with treatment by anti-25-depleting antibody to deplete Tregs ${ }^{24}$; conversely, adaptive transplantation of Tregs could lead to reduced disease activity ${ }^{25-27}$. We previously reported that the absolute count of Tregs was significantly lower in patients with DM/PM (both new and previously treated patients) compared with healthy subjects, while there was no significant difference between new and previously treated patients ${ }^{16}$. In other autoimmune diseases similar to RA, deficient immune tolerance mediated by depletion of circulating Tregs also contributes to the disease ${ }^{172028}$. In addition, autoantibodies, such as RF and anti-MCV, were higher in patients with active RA, and were significantly correlated with markers of disease activity. Follicular Th cells are involved in the generation of high-affinity antibodies characteristic of RA, such as $\mathrm{RF}$, anti-CCP, and anti-MCV, which can be suppressed with elevated expression of Tregs $^{29}$. The mechanism of deficient immune tolerance mediated mainly by peripheral Tregs in RA patients has been unclear in previous studies, possibly due to decreased absolute counts of peripheral Tregs caused by Tregs migrating and presenting in inflamed joints during inflammatory responses ${ }^{30}$, or to the dysfunction of Tregs induced by IL-2 deficiency in patients with RA ${ }^{13} 31$ 32. In addition, previous immunosuppressive drugs, such as methotrexate and leflunomide, as well as glucocorticoid, can lead to or exacerbate deficiency in Tregs or other CD4 + T lymphocyte subpopulations, thereby increasing the risk of infections and tumors ${ }^{33-35}$. Therefore, immunoregulation regimens targeting Tregs, such as supplementation with exogenous IL-2 (or transfer of Tregs) to restore self-tolerance, may provide a new avenue for treating Tregmediated diseases, such as RA. IL-2 has been shown to influence T cells differentiation in a dose- 
dependent way ${ }^{9}$. In our previous studies, the efficacy and safety of low-dose IL-2 for peripheral Tregs proliferation and disease remission were confirmed in patients with $\mathrm{PSA}^{15}, \mathrm{DM} / \mathrm{PM}^{16}$ and primary SS ${ }^{17}$, without evaluated side effects.

Low-dose IL-2 in patients with RA can reduce disease activity by restoring immune tolerance and promoting the proliferation of circulating Tregs, without obvious adverse reactions or side effects. When the disease was gradually relieved, pro-inflammatory markers, such as Th17 cells, also increased significantly, which further confirmed that Tregs were the main lymphocyte subgroup involved in the pathogenesis of RA. Rosenzwajg ${ }^{9}$ reported that all autoimmune and inflammatory diseases are associated with insufficient Tregs; low-dose IL-2 selectively and safely activated and increased Tregs in 11 autoimmune diseases, although only three subjects with RA were enrolled. Other studies have reported that low-dose IL-2 may also amplify Tregs and natural killer cells, thus sustaining cellular immunity, and is a well-tolerated treatment for $\mathrm{SLE}^{20}{ }^{36}$, consistent with the results of Rosenzwajg ${ }^{9}$. Thus, the safety and efficacy of IL-2 has been demonstrated in different diseases without serious adverse treatment-related effects; however, the mechanism of IL-2 still needs further study. Although the present study included a large number of samples, long-term follow-up is needed to further confirm the efficacy and safety of lowdose IL-2 combination treatment.

In conclusion, decreased absolute counts of circulating CD4 + T lymphocyte subsets were observed in patients with RA. Moreover, circulating Tregs, which mediate immune tolerance, may be involved in the pathogenesis and progression of RA and can be restored by low-dose IL-2 without obvious side effects.

\section{Declarations}

\section{Competing interests}

The authors declare that they have no competing interests.

\section{Ethics approval and consent to participate}

This study was approved by the Ethics Committee of the Second Hospital of Shanxi Medical University (2016 KY-007).

\section{Consent for publication}

Not Applicable.

\section{Authors contributions}

Study design and manuscript writing: SZ and JW. Data extraction, quality assessment, analysis and interpretation of data: CW, RJ and MY. All authors were involved in drafting the article or revising it critically for important intellectual content, and all authors approved the final version to be published. Dr. 
Li had full access to all of the data in the study and takes responsibility for the integrity of the data and the accuracy of the data analysis.

\section{Funding}

This work was supported by the National Natural Science Foundation of China (No. 82001740).

\section{Availability of data and materials}

All data generated or analyzed during this study are included in this published article.

\section{Acknowledgments}

Not Applicable.

\section{References}

1. Malemud CJ. Defective T-Cell Apoptosis and T-Regulatory Cell Dysfunction in Rheumatoid Arthritis. Cells 2018;7(12) doi: 10.3390/cells7120223 [published Online First: 2018/11/25]

2. Dadoun S, Zeboulon-Ktorza N, Combescure $\mathrm{C}$, et al. Mortality in rheumatoid arthritis over the last fifty years: systematic review and meta-analysis. Joint Bone Spine 2013;80(1):29-33. doi: 10.1016/j.jbspin.2012.02.005 [published Online First: 2012/03/31]

3. Smolen JS, van der Heijde D, Machold KP, et al. Proposal for a new nomenclature of diseasemodifying antirheumatic drugs. Ann Rheum Dis 2014;73(1):3-5. doi: 10.1136/annrheumdis-2013204317 [published Online First: 2013/09/28]

4. Holmdahl R, Malmstrom V, Burkhardt H. Autoimmune priming, tissue attack and chronic inflammation - the three stages of rheumatoid arthritis. Eur J Immunol 2014;44(6):1593-9. doi: 10.1002/eji.201444486 [published Online First: 2014/04/17]

5. Kobezda T, Ghassemi-Nejad S, Mikecz K, et al. Of mice and men: how animal models advance our understanding of T-cell function in RA. Nat Rev Rheumatol 2014;10(3):160-70. doi: 10.1038/nrrheum.2013.205 [published Online First: 2014/01/08]

6. Sakaguchi S, Yamaguchi T, Nomura T, et al. Regulatory $T$ cells and immune tolerance. Cell 2008;133(5):775-87. doi: 10.1016/j.cell.2008.05.009 [published Online First: 2008/05/31]

7. Szentpetery A, Heffernan E, Gogarty $M$, et al. Abatacept reduces synovial regulatory T-cell expression in patients with psoriatic arthritis. Arthritis Res Ther 2017;19(1):158. doi: 10.1186/s13075-017-13643 [published Online First: 2017/07/07]

8. Miyara M, Ito Y, Sakaguchi S. TREG-cell therapies for autoimmune rheumatic diseases. Nat Rev Rheumatol 2014;10(9):543-51. doi: 10.1038/nrrheum.2014.105 [published Online First: 2014/07/02]

9. Rosenzwajg M, Lorenzon R, Cacoub P, et al. Immunological and clinical effects of low-dose interleukin-2 across 11 autoimmune diseases in a single, open clinical trial. Ann Rheum Dis 2019;78(2):209-17. doi: 10.1136/annrheumdis-2018-214229 [published Online First: 2018/11/26] 
10. Dulic S, Vasarhelyi Z, Sava F, et al. T-Cell Subsets in Rheumatoid Arthritis Patients on Long-Term AntiTNF or IL-6 Receptor Blocker Therapy. Mediators Inflamm 2017;2017:6894374. doi:

10.1155/2017/6894374 [published Online First: 2017/12/07]

11. Morgan DA, Ruscetti FW, Gallo R. Selective in vitro growth of T lymphocytes from normal human bone marrows. Science 1976;193(4257):1007-8. doi: 10.1126/science.181845 [published Online First: 1976/09/10]

12. Minami Y, Kono T, Miyazaki T, et al. The IL-2 receptor complex: its structure, function, and target genes. Annu Rev Immunol 1993;11:245-68. doi: 10.1146/annurev.iy.11.040193.001333 [published Online First: 1993/01/01]

13. Suzuki $H$, Kundig TM, Furlonger $C$, et al. Deregulated $T$ cell activation and autoimmunity in mice lacking interleukin-2 receptor beta. Science 1995;268(5216):1472-6. doi: 10.1126/science.7770771 [published Online First: 1995/06/09]

14. Ross SH, Cantrell DA. Signaling and Function of Interleukin-2 in T Lymphocytes. Annu Rev Immunol 2018;36:411-33. doi: 10.1146/annurev-immunol-042617-053352 [published Online First: 2018/04/21]

15. Wang J, Zhang SX, Hao YF, et al. The numbers of peripheral regulatory T cells are reduced in patients with psoriatic arthritis and are restored by low-dose interleukin-2. Ther Adv Chronic Dis 2020;11:1-12. doi: $10.1177 / 2040622320916014$

16. Zhang SX, Wang J, Sun $\mathrm{HH}$, et al. Circulating regulatory $\mathrm{T}$ cells were absolutely decreased in dermatomyositis/polymyositis patients and restored by low-dose IL-2. Ann Rheum Dis 2019 doi: 10.1136/annrheumdis-2019-216246 [published Online First: 2019/10/16]

17. Miao M, Hao Z, Guo Y, et al. Short-term and low-dose IL-2 therapy restores the Th17/Treg balance in the peripheral blood of patients with primary Sjogren's syndrome. Ann Rheum Dis 2018;77(12):183840. doi: 10.1136/annrheumdis-2018-213036 [published Online First: 2018/06/25]

18. Aletaha D, Neogi T, Silman AJ, et al. 2010 rheumatoid arthritis classification criteria: an American College of Rheumatology/European League Against Rheumatism collaborative initiative. Ann Rheum Dis 2010;69(9):1580-8. doi: 10.1136/ard.2010.138461

19. Arnett FC, Edworthy SM, Bloch DA, et al. The American Rheumatism Association 1987 revised criteria for the classification of rheumatoid arthritis. Arthritis Rheum 1988;31(3):315-24.

20. He J, Zhang R, Shao M, et al. Efficacy and safety of low-dose IL-2 in the treatment of systemic lupus erythematosus: a randomised, double-blind, placebo-controlled trial. Ann Rheum Dis 2019 doi:

10.1136/annrheumdis-2019-215396 [published Online First: 2019/09/21]

21. Byng-Maddick R, Ehrenstein MR. The impact of biological therapy on regulatory $T$ cells in rheumatoid arthritis. Rheumatology (Oxford) 2015;54(5):768-75. doi: 10.1093/rheumatology/keu487 [published Online First: 2015/02/11]

22. Cooles FA, Isaacs JD, Anderson AE. Treg cells in rheumatoid arthritis: an update. Curr Rheumatol Rep 2013;15(9):352. doi: 10.1007/s11926-013-0352-0 [published Online First: 2013/07/28] 
23. Alunno A, Manetti M, Caterbi S, et al. Altered immunoregulation in rheumatoid arthritis: the role of regulatory T cells and proinflammatory Th17 cells and therapeutic implications. Mediators Inflamm 2015;2015:751793. doi: 10.1155/2015/751793 [published Online First: 2015/04/29]

24. Morgan ME, Sutmuller RP, Witteveen HJ, et al. CD25+ cell depletion hastens the onset of severe disease in collagen-induced arthritis. Arthritis Rheum 2003;48(5):1452-60. doi: 10.1002/art.11063 [published Online First: 2003/05/15]

25. Frey $\mathrm{O}$, Petrow PK, Gajda M, et al. The role of regulatory $T$ cells in antigen-induced arthritis: aggravation of arthritis after depletion and amelioration after transfer of CD4+CD25+ T cells. Arthritis Res Ther 2005;7(2):R291-301. doi: 10.1186/ar1484 [published Online First: 2005/03/04]

26. Morgan ME, Flierman R, van Duivenvoorde LM, et al. Effective treatment of collagen-induced arthritis by adoptive transfer of CD25+ regulatory T cells. Arthritis Rheum 2005;52(7):2212-21. doi: 10.1002/art.21195 [published Online First: 2005/06/30]

27. Walter GJ, Fleskens V, Frederiksen KS, et al. Phenotypic, Functional, and Gene Expression Profiling of Peripheral CD45RA+ and CD45RO+ CD4+CD25+CD127(low) Treg Cells in Patients With Chronic Rheumatoid Arthritis. Arthritis Rheumato/ 2016;68(1):103-16. doi: 10.1002/art.39408 [published Online First: 2015/09/01]

28. Li YF, Zhang SX, Ma XW, et al. The proportion of peripheral regulatory T cells in patients with Multiple Sclerosis: A meta-analysis. Mult Scler Relat Disord 2019;28:75-80. doi: 10.1016/j.msard.2018.12.019 [published Online First: 2018/12/21]

29. Liu C, Wang D, Lu S, et al. Increased Circulating Follicular Treg Cells Are Associated With Lower Levels of Autoantibodies in Patients With Rheumatoid Arthritis in Stable Remission. Arthritis Rheumato/ 2018;70(5):711-21. doi: 10.1002/art.40430 [published Online First: 2018/01/31]

30. Penatti A, Facciotti F, De Matteis R, et al. Differences in serum and synovial CD4+ T cells and cytokine profiles to stratify patients with inflammatory osteoarthritis and rheumatoid arthritis. Arthritis Res Ther 2017;19(1):103. doi: 10.1186/s13075-017-1305-1 [published Online First: 2017/05/21]

31. Malek TR, Yu A, Vincek V, et al. CD4 regulatory T cells prevent lethal autoimmunity in IL-2Rbetadeficient mice. Implications for the nonredundant function of IL-2. Immunity 2002;17(2):167-78.

32. Humrich JY, von Spee-Mayer C, Siegert E, et al. Rapid induction of clinical remission by low-dose interleukin-2 in a patient with refractory SLE. Annals of the rheumatic diseases 2015;74(4):791-2. doi: 10.1136/annrheumdis-2014-206506

33. Whitley NT, Day MJ. Immunomodulatory drugs and their application to the management of canine immune-mediated disease. J Small Anim Pract 2011;52(2):70-85. doi: 10.1111/j.17485827.2011.01024.x [published Online First: 2011/01/27]

34. Furiati SC, Catarino JS, Silva MV, et al. Th1, Th17, and Treg Responses are Differently Modulated by TNF-alpha Inhibitors and Methotrexate in Psoriasis Patients. Scientific reports 2019;9(1):7526. doi: 10.1038/s41598-019-43899-9 [published Online First: 2019/05/19] 
35. Cronstein BN. Molecular therapeutics. Methotrexate and its mechanism of action. Arthritis Rheum 1996;39(12):1951-60. doi: 10.1002/art.1780391203 [published Online First: 1996/12/01]

36. He J, Zhang X, Wei Y, et al. Low-dose interleukin-2 treatment selectively modulates CD4(+) T cell subsets in patients with systemic lupus erythematosus. Nature medicine 2016;22(9):991-3. doi: $10.1038 / \mathrm{nm} .4148$

\section{Figures}
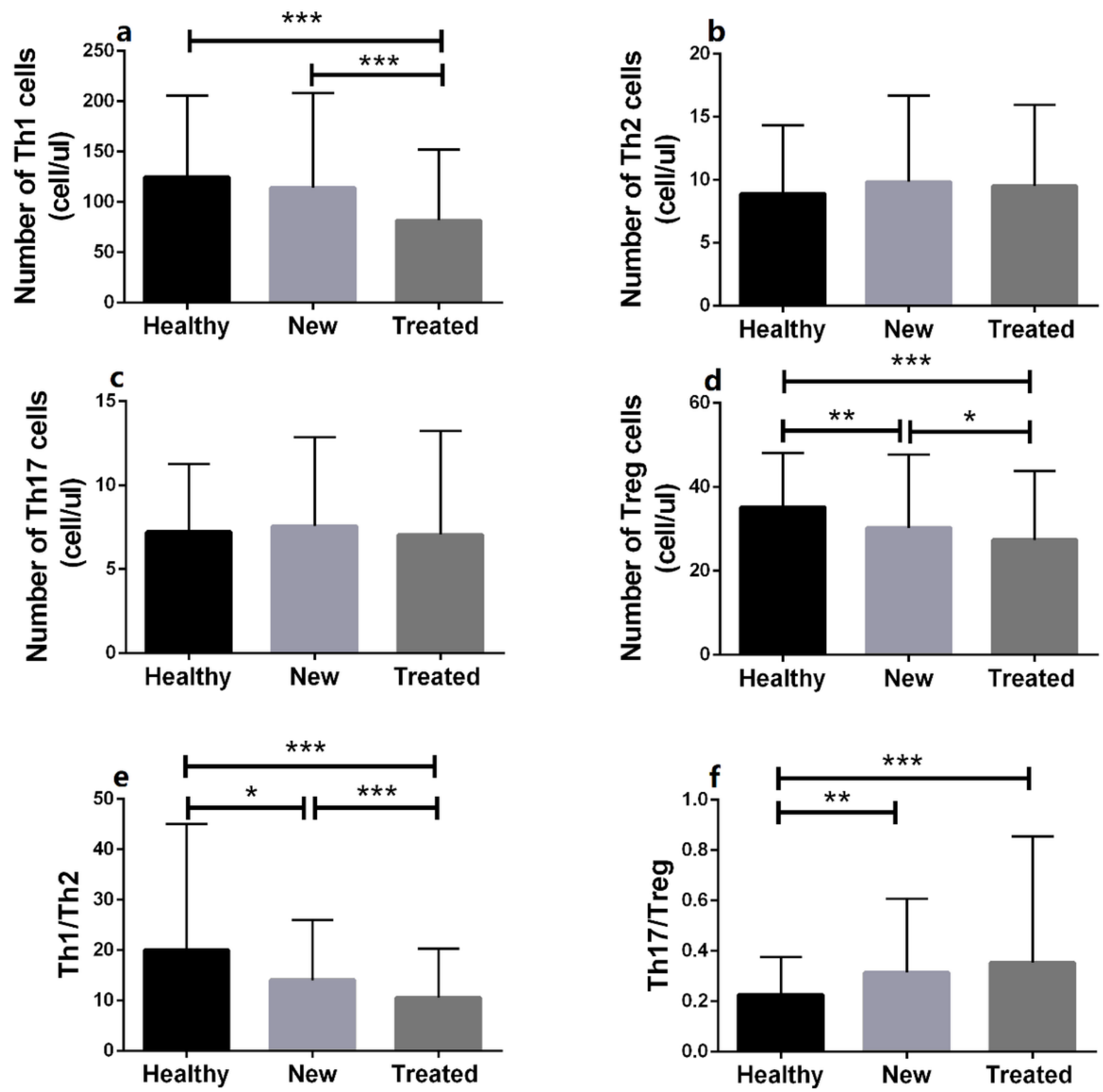

Figure 1 
Changes in the absolute counts of peripheral CD4+T subsets among new $(n=188)$ and previously treated $(n=700)$ patients with RA and healthy controls $(n=100)$. (a) The absolute count of Th1 cells from previously treated patients with RA was significantly lower than that of healthy individuals and new RA patients. New RA patients had a similar level of Th1 cells as healthy controls. (b and c) There were no significant differences in the absolute counts of Th2 or Th17 cells between RA patients and healthy controls. (d) RA patients, both new and previously treated, had decreased absolute counts of Tregs compared with healthy controls; the fewest circulating Tregs were from previously treated RA patients. (e and f) The Th1/Th2 ratio was significantly lower, and the Th17/Treg ratio significantly higher, in patients with RA. Previously treated patients had the lowest Th1/Th2 ratio. ${ }^{*} P<0.05,{ }^{\star} * \mathrm{P}<0.01,{ }^{\star} * \star \mathrm{P}<0.001$. Significance values are asymptotic (2-sided tests) and the significance level is $P<0.05$. 

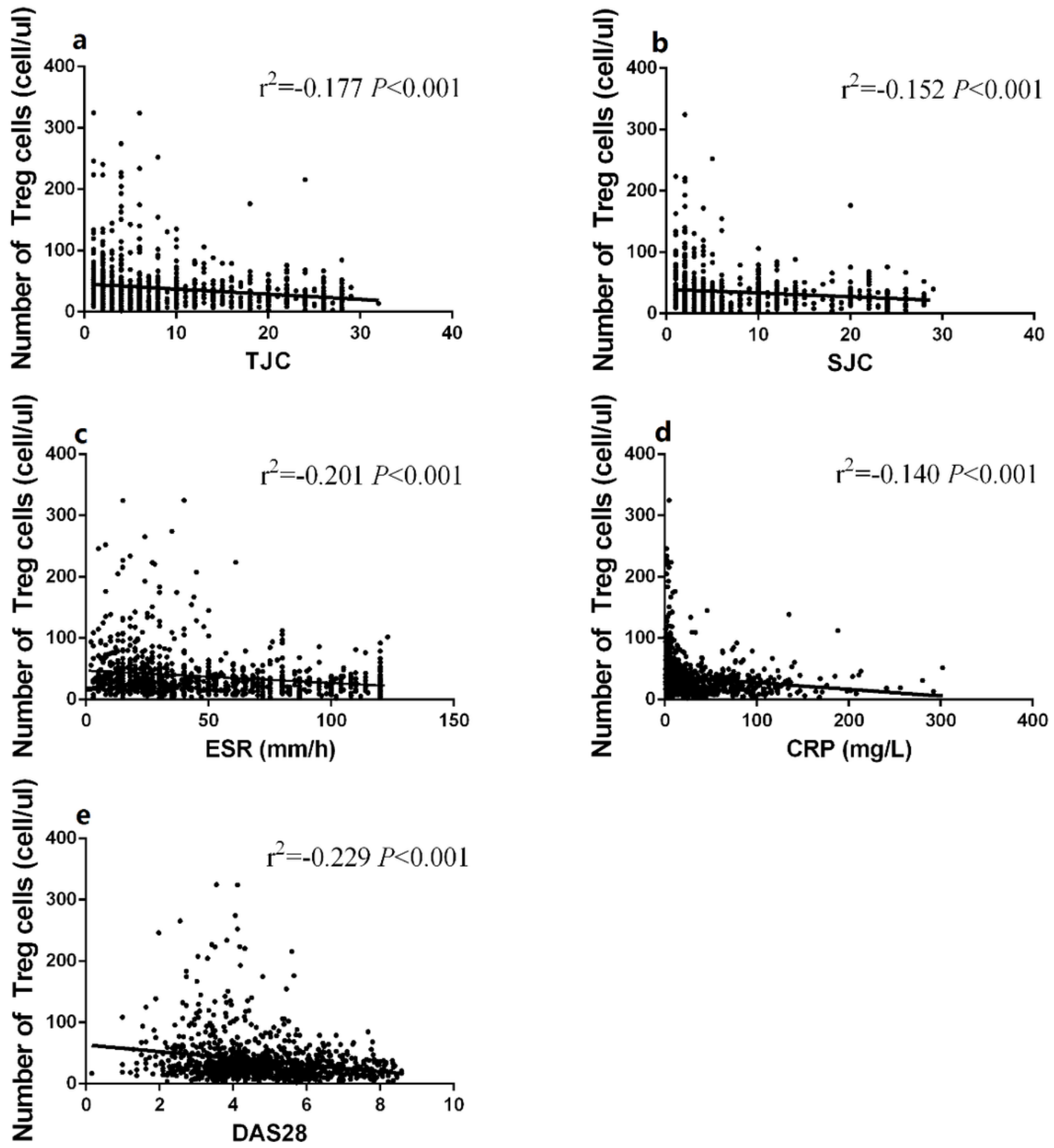

Figure 2

Correlation between the absolute count of circulating Tregs and disease activity. (a-e) The absolute count of Tregs in peripheral blood was negatively correlated with markers of disease activity, including TJC, SJC, ESR, CRP, and DAS28, in patients with RA. ${ }^{*} P<0.05$, $* * P<0.01$, $* \star * P<0.001$. Significance values are asymptotic (2-sided tests) and the significance level is $P<0.05$. ESR: erythrocyte sedimentation rate; 
CRP: C-reactive protein; TJC: tender joint counts; SJC: swollen joint counts; DAS28: Disease Activity Score28; Treg: regulatory $\mathrm{T}$ cells.
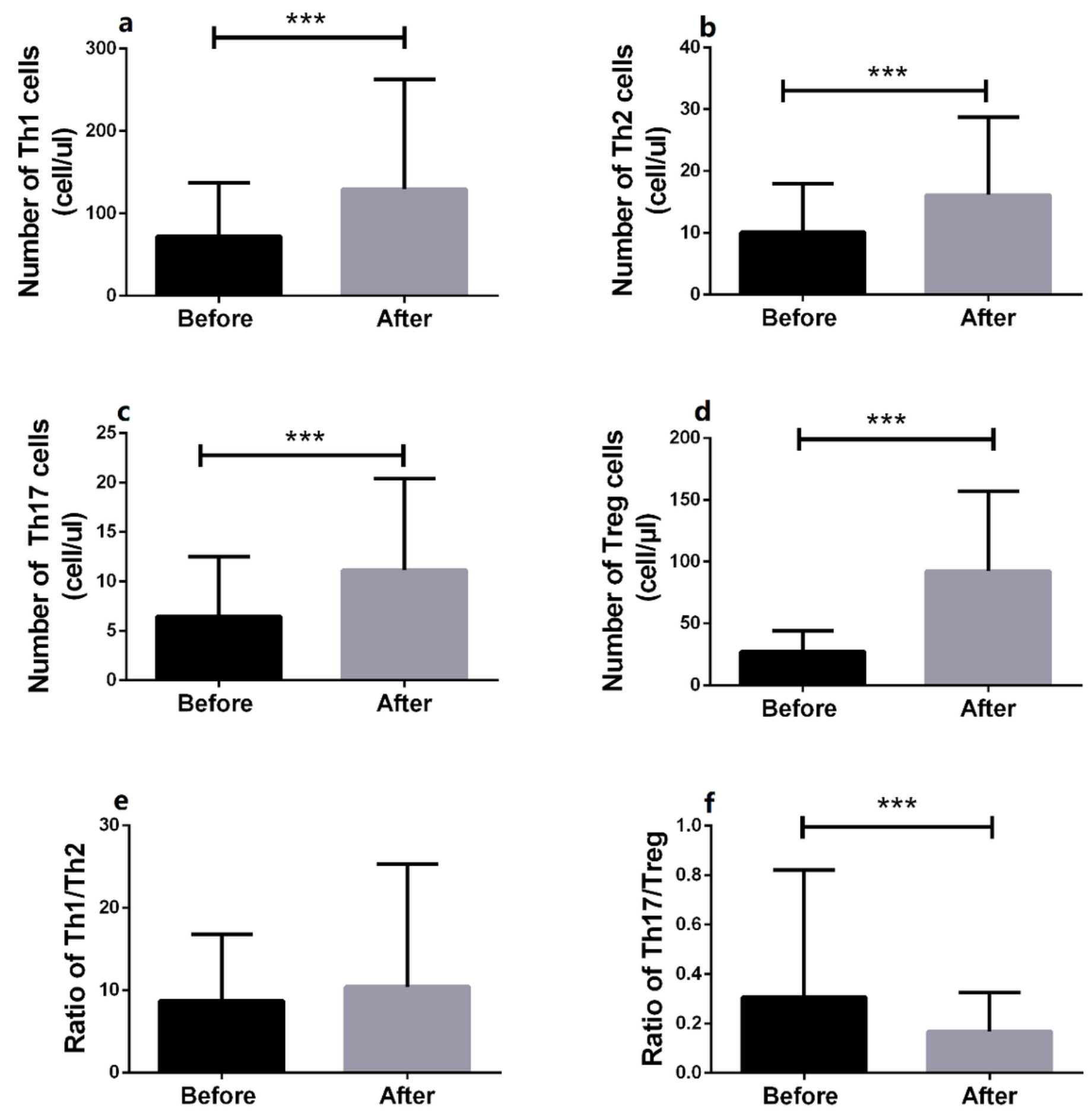

Figure 3

Efficacy of short-term, low-dose IL-2 treatment in regulating levels of CD4+T subsets. (a-d) Absolute counts of peripheral CD4+T subsets, especially Tregs, were significantly higher in RA patients after IL-2 treatment compared with the baseline. (e and f) The Th17/Treg ratio decreased significantly in RA patients after IL-2 treatment, whereas the ratio of Th1/Th2 was not significantly different. Within-group 
comparisons were made using the paired samples t-test before and after IL-2 therapy. ${ }^{\star \star \star} P<0.001$. Significance values are asymptotic (2-sided tests) and the significance level is $P<0.05$.

\section{Supplementary Files}

This is a list of supplementary files associated with this preprint. Click to download.

- supplementary.docx 